\title{
PROPOSTA DE APLICABILIDADE DA PRESERVAÇÃO Digital AO PRONTUÁRIO ELETRÔNICO dO PACIENTE
}

\author{
APLICABILITY PROPOSAL FOR DIGITAL PRESERVATION OF \\ PATIENTS' ELECTRONIC RECORDS
}

PROPUESTA DE APLICABILIDAD DE LA PRESERVACIÓN DIGITAL A LA HISTORIA

CLINICA ELECTRONICA DEL PACIENTE

1Virginia Bentes Pinto, ${ }^{1}$ Odete Máyra Mesquita Sales

1Universidade Federal do Ceará

\section{Correspondência}

1Virginia Bentes Pinto

Universidade Federal do Ceará

Fortaleza, CE

Email: vbentes@ufc.br

ORCID: http://orcid.org/0000-0003-1283-

$\underline{8292}$

Submetido em: $31-07-2016$

Aceito em: 15-02-2017

Publicado: 07-04-2017

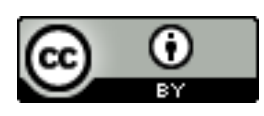

JITA: JH. Digital preservation 
RESUMO: Apresentam-se os resultados preliminares de uma pesquisa sobre a preservação e a curadoria digital, bem como a possibilidade de aplicabilidade ao contexto da documentação sanitária, enquanto memória da saúde. A pesquisa teve por base a seguinte questão: Como o padrão Open Archival Information System (OAIS) pode ser aplicado aos prontuários eletrônicos do paciente, na perspectiva da preservação de conteúdos digitais, visando a assegurar a confidencialidade, confiabilidade, autenticidade e acesso, a quem de direito, à informação registrada nesses documentos? O objetivo básico é estudar a literatura referente à preservação e à curadoria digital, com ênfase no padrão OAIS, considerando a possibilidade de sua aplicação para o desenvolvimento de um Repositório Digital de Prontuários Eletrônicos de Paciente, observando-se o ordenamento jurídico concernente a esse tipo de documento. Pesquisa exploratória pautada no levantamento do estado da arte sobre o tema em lide. O corpus do estudo foi constituído de 01 (um) prontuário (cinco volumes) da especialidade da nefrologia, com recorte no ano de 1970. O estudo empírico foi no Serviço de Arquivo Médico e Estatística, do Hospital Universitário Walter Cantídio da Universidade Federal do Ceará. Os achados evidenciam que, embora já existam várias iniciativas sobre a preservação digital da documentação cientifica tecnológica e cultural, não encontramos experiências sobre prontuários. Ademais, o modelo OAIS pode ser aplicado ao contexto do prontuário eletrônico do paciente desde que observadas às características particulares de legalidade de acesso a esses documentos, bem como os requisitos e/ou diretrizes para implementação de um Repositório Digital para Prontuário Eletrônico de Paciente.

PALAVRAS-CHAVE: Preservação digital. Prontuário eletrônico do paciente. Curadoria digital.

ABSTRACT: We present the preliminary results of a research on digital preservation and curation, as well as the possibility of applicability to the context of health documentation, as a memory of health. The research was based on the following question: How can the Open Archival Information System (OAIS) standard be applied to patients' electronic records, with a view to preserving digital contents, to ensure confidentiality, reliability, authenticity and access to who rightly owns the information recorded in these documents? The basic objective is to study the literature regarding preservation and digital curation, with emphasis on the OAIS standard, considering the possibility of its application for the development of a Digital Repository of Electronic Patient Records, observing the legal order concerning this type of document. Exploratory research based on the state of the art survey on the topic under discussion. The corpus of the study consisted of 01 (one) medical record (five volumes) of the specialty of nephrology, focusing on the year of 1970. The empirical study was in the Medical and Statistical Archive Service, Walter Cantídio University Hospital of the Federal University of Ceará. The findings show that, although there are already several initiatives on the digital preservation of scientific technological and cultural documentation, we did not find experiences on medical records. Furthermore, the OAIS model can be applied to the context of the patient's electronic medical records, provided the particular characteristics of legality of access to these documents are observed, as well as the requirements and/or guidelines for implementing a Digital Repository for Electronic Patient Records.

KEYWORDS: Digital preservation. Electronic patient records. Digital curation.

RESUMEN: Se presentan los resultados preliminares de una investigación sobre la preservación y la curaduría digital, bien como la posibilidad de aplicabilidad al contexto de la documentación sanitaria, mientras que memoria de la salud. El problema de la investigación es: ¿Cómo se puede aplicar el estándar Sistema de Información de Archivo Abierto (OAIS) a las historias clínicas electrónicos del paciente, en la perspectiva de la preservación del contenido digital, con el propósito de asegurar la confidencialidad, la confiabilidad, la autenticidad y el acceso, a quién tiene el derecho, a la información registrada en estos documentos? El objetivo básico es estudiar la literatura concerniente a la preservación y la curaduría digital, con énfasis en el estándar OAIS, teniendo en cuenta la posibilidad de su uso para el desarrollo de un Repositorio digital de las historias clínicas electrónicas del paciente, observándose el ordenamiento jurídico de este tipo de documento. Es una investigación exploratoria basada en el análisis del estado del arte sobre el tema. El corpus del estudio fue constituido de 01 (una) historia clínica electrónica del paciente (cinco volúmenes) de la especialidad del nefrología, concerniente el año de 1970. El estudio empírico ha sido hecho en el servicio del archivo médico y estadística, del hospital Walter Cantídio de la Universidad Federal del Caerá. Los resultados evidencian que, sin embargo algunas iniciativas ya existen la preservación digital de la documentación científica tecnológica y cultural, pero no han sido encontradas experiencias en las historias clínicas electrónicas del paciente. Además, el estándar OAIS se puede aplicar al contexto de esto documentación desde que se observen las características particulares de su legalidad del acceso, así como los requisitos y/o las directrices para sé colocar en práctica un repositorio Digital para las historias clínicas electrónicas del paciente.

PAlABRAS Clave: Preservación Digital. Historias clínicas electrónicas del paciente. Curaduria digital.

\begin{tabular}{l|c|c|c|c|c}
\hline (C) RDBCI: Rev. Digit. Bibliotecon. Cienc. Inf. & Campinas, SP & v.15 & n.2 & p. 489-507 & maio/ago. 2017 \\
\hline
\end{tabular}




\section{INTRODUÇÃO}

\begin{abstract}
La question de l'archive n'est pas une question du passé. Ce n'est pas la question d'un concept dont nous disposerions ou ne disposerions pas déjà au sujet du passé, un concept archivable d'archive. C'est une question d'avenir, la question de l'avenir même, la question d'une réponse, d'une promesse et d'une responsabilité pour demain. L'archive, si nous voulons savoir ce que cela aura voulu dire, nous ne le saurons que dans le temps à venir. Peut-être. Non pas demain mais dans les temps à venir, tout à l'heure ou peut-être jamais.
\end{abstract}

Jacques Derrida

O discurso contundente do filósofo Jacques Derrida chama atenção para a necessidade ímpar de se preservar a documentação para gerações futuras. Na área da Saúde, tal prática torna-se fundamental, não somente em relação aos resultados de pesquisas cientificas, porém, também, dos Prontuários Eletrônicos do Paciente (PEP), em face do frequente aparecimento de novas doenças como também do ressurgimento de outras, quase sempre com características inovadas e, muitas vezes, bem mais potentes. A preservação do PEP - representante maior da chamada documentação sanitária - garantiria a realização de pesquisas e estudos comparativos embasados nessas fontes que visassem investigar o surgimento dessas doenças ou se elas se 'inovam' bem como as medidas terapêuticas postas em execução tendo em vista a sua cura ou, ainda, as orientações prescritas para se conviver com elas. Portanto, a decisão em torno de uma política de preservação desses documentos é sine qua non tanto para a medicina baseada em evidências como para as pesquisas, ensino e provas jurídicas, quando de questões relativas a um tratamento, a uma conduta ética ou a outro fator.

Ao se considerar a trajetória da preservação da informação, sabe-se que ela acompanha a história da humanidade desde os mais remotos registros do conhecimento em suportes da época, a exemplo daqueles feitos nas paredes de cavernas, papiros e pergaminhos. Contudo, no âmbito da Biblioteconomia e da Ciência da Informação, tem-se como marcos da preservação o Catálogo da Biblioteca de Alexandria, elaborado por Calímaco, e a publicação da Bibliotheca universalis, em 1545, por Conrad Gesner. Na educação formal dessas áreas, destaca-se a obra intitulada Cours de bibliographie, de Louise-Noelle Malclès, publicada em 1954. Mas, efetivamente, o avanço em preservação da documentação ocorreu a partir do estabelecimento de políticas elaboradas pela United Nations Educational Scientific and Cultural Organizations (UNESCO) e pela Federação Internacional de Associações de Bibliotecários (IFLA), editadas em 1970.

Essas políticas estabelecem como objetivo reunir e disponibilizar os registros da produção bibliográfica de todos os países em uma rede internacional de informação, considerando a possibilidade de conhecer a existência do documento, sua localização e acesso. Essas ações vieram prescritas nas propostas e métodos tradicionais de Controle Bibliográfico Universal por meio da institucionalização do 'depósito legal' ainda em vigor nas bibliotecas nacionais dos diferentes países do mundo.

\begin{tabular}{c|c|c|c|c|c}
\hline (C) RDBCI: Rev. Digit. Bibliotecon. Cienc. Inf. & Campinas, SP & v.15 & n.2 & p. 489-507 & maio/ago. 2017 \\
\hline
\end{tabular}


Porém, diante da grande produção de registros de conhecimentos em suportes digitais proporcionada pelas novíssimas tecnologias eletrônicas e digitais de informação e de comunicação, essa certeza de segurança já começa a ser questionada. Segundo Térmens (2013), o suporte digital é frágil e ainda não se tem confirmação de segurança quanto à sua preservação, em longo prazo, devido à degradação da matéria-prima utilizada em sua fabricação e da obsolescência das mídias tecnológicas de registro de armazenamento e de custos envolvidos. Além, dessas características, também não se pode deixar de mencionar as competências dos bibliotecários, arquivistas e museólogos para atuar nesse novo nicho de trabalho.

Em face desta problemática, a Organização das Nações Unidas para a Ciência e Cultura (UNESCO) saiu à frente dessas questões e lançou, em 2003, a 'Carta sobre a Preservação Digital' e as 'Recomendações sobre Software Livre para Repositório e Sistema de Preservação', em 2007. Conforme o Guia da UNESCO (2003, p. 28-30), a preservação digital configura-se como o conjunto de atividades ou processos responsáveis por garantir o acesso continuado, em longo prazo, à informação e ao patrimônio cultural existente em formatos digitais. Na percepção de Arellano (2008, p. 23), tal preservação não se configura apenas em sequências da cadeia de bits. Ao contrário, associa-se ao "[...] conjunto de decisões que definiram a formação básica do objeto informacional como um objeto único" e, mais ainda, envolve a "[...] determinação de metadados digitais dos conteúdos dos documentos, nas informações armazenadas e na maneira como foram armazenadas". Em outras palavras, está no cerne das ações teóricas e pragmáticas das disciplinas que compõem a área da Ciência da Informação, principalmente, associada tanto à representação descritiva e temática da informação como também à mediação e gestão.

Já existem vários modelos de metadados de preservação, destacando-se entre eles o padrão Open Archival Information System (OAIS) que propõe descrever um quadro conceitual para um sistema completo e universal de guarda permanente de documentos digitais e especifica como os documentos digitais devem ser preservados desde sua inserção no repositório digital até sua disponibilização para acesso pelo usuário final (FLORES; HEDLUND, 2014). Porém, em se tratando do prontuário do paciente, não encontramos literatura abordando diretamente esse tema.

Eis aí uma das motivações para investigar sobre esse objeto de estudo, tomando-se por base o seguinte questionamento: Como o padrão OAIS pode ser aplicado aos prontuários eletrônicos do paciente, na perspectiva da preservação de conteúdos digitais, visando a assegurar a confidencialidade, confiabilidade, autenticidade e acesso, a quem de direito, à informação registrada nesses documentos? Na busca de respostas a esse problema de pesquisa, definimos como objetivo estudar a literatura referente à preservação e à curadoria digital, com ênfase no padrão OAIS, tendo em vista considerar a possibilidade de sua aplicação para o desenvolvimento de um Repositório Digital de Prontuários Eletrônicos de Paciente, que 
contemple a confidencialidade, confiabilidade, autenticidade e acesso à recuperação da informação, observando-se o ordenamento jurídico concernente a esse documento.

A metodologia adotada nesta pesquisa evidencia tratar-se de um estudo exploratório de natureza qualitativa, tendo o método funcionalista como sustentação para nossa análise, posto que, conforme Kruppa (1994, p. 55), esse método entende a sociedade como um "[...] organismo vivo, um todo integrado, onde cada parte desempenha uma função necessária ao equilíbrio do todo". Ao ser aplicado tal conceito ao Prontuário Eletrônico do Paciente, pode-se inferir que ele se configura como um organismo cuja estrutura é constituída por um conjunto de documentos com os registros necessários para que se conheça as enfermidades a que os pacientes estão confrontados bem como as ações a serem ou que já foram implementadas em prol da cura das doenças e do restabelecimento do paciente ao estado de normalidade.

Para o estudo dos prontuários, baseamo-nos na análise de conteúdos registrados nesses documentos, a fim de que fosse possível estruturar algumas categorias que possibilitarão a aplicabilidade do padrão OAIS. O corpus do estudo foi constituído de um (01) prontuário (cinco volumes) da especialidade nefrologia, tendo-se como recorte/delimitação o ano de 1970. O locus do estudo empírico é o Serviço de Arquivo Médico e Estatística (SAME) do Hospital Universitário Walter Cantídio da Universidade Federal do Ceará.

\section{DIÁlOgOS BIBLIOGRÁFICOS SOBRE PRESERVAÇÃo DIGITAL}

Para efeito deste artigo, consideramos importante explicitar nosso entendimento sobre preservação. Tal conceito remete-nos à ideia de salvaguardar coisas e objetos do mundo bem como às relações de afetividade entre os sujeitos. Configura-se como uma espécie de cuidado, de amparo de defesa, no sentido amplo do termo. Porém, no ambiente científico, Silva (1998, p. 2) apresenta como conceito de preservação "[...] toda ação que se destina a salvaguardar ou recuperar as condições físicas [dos documentos] e proporcionar a permanência aos materiais dos suportes $[\ldots] "$.

Em que concerne à preservação digital, ela surge com a predominância do meio eletrônico e de sua 'transversalidade' nas práticas cotidianas e em todas as dimensões da vida (TAVARES, 2012). Não se trata de um modismo, porém, de uma nova cultura que precisa ser incentivada, a fim de que o patrimônio documental cultural científico e técnico não venha a se perder. Avançando nessa discussão, Hedstrom (1996, p. 189) afirma que a preservação digital se refere ao "[...] planejamento, alocação de recursos e aplicação de métodos e tecnologias para assegurar que a informação digital de valor contínuo permaneça acessível e utilizável $[\ldots]^{\prime \prime}$.

Por seu turno, Waters e Garrett (1996) apresentam o conceito de preservação digital associado aos aspectos intelectuais do documento, sua integridade e acessibilidade da 
informação em longo prazo. Esses autores defendem ainda que "[...] a preservação de integridade e acessibilidade não se limita, apenas, a proteger a informação digital contra o acesso não autorizado [...]", mas também "[...] contra o uso inadequado resultante da má interpretação ou má representação da informação por parte dos sistemas computacionais [...]”, ao que nós acrescentamos também a intervenção humana. A Organização das Nações Unidas para a Ciência e Cultura (UNESCO, 2003, p. 18) amplia esse conceito, ao esclarecer que a preservação digital "[...] é usada para descrever os processos envolvidos na manutenção de informações e de outros tipos de patrimônios existentes em forma digital”.

Com base no conceito formulado pela UNESCO, Arellano (2008, p. 30), em suas reflexões, argumenta que uma efetiva preservação digital demanda a adoção de condições básicas, métodos e tecnologias que permitam integrar os níveis de preservação "[...] física, lógica e intelectual dos objetos digitais". Conforme o autor, a preservação física centra-se "[...] nos conteúdos armazenados em mídia magnética (fitas cassete de áudio e de rolo, fitas VHS e DAT) e discos óticos (CD-ROM, WORM e discos óticos regraváveis)". Em relação à preservação lógica, busca "[...] na tecnologia, formatos atualizados para inserção dos dados (correio eletrônico, material de áudio e audiovisual e material em rede), novos software e hardware que mantenham vigentes seus bits, para conservar sua capacidade de leitura", ao passo que no contexto da preservação intelectual o "[...] foco são os mecanismos que garantem a integridade e a autenticidade da informação nos documentos eletrônicos". Nessa linha, o Conselho Nacional de Arquivo (CONARQ, 2009, 15) defende que “[...] O desafio da preservação dos documentos arquivísticos digitais está em garantir o acesso contínuo a seus conteúdos e funcionalidades, por meio de recursos tecnológicos disponíveis à época em que ocorrer a sua utilização.” Esse desafio se aplica a outras categorias de documentos.

Consideramos que nesse tipo de preservação também devem ser observadas as questões de Propriedade Intelectual, porquanto a vulnerabilidade desses documentos pode gerar prejuízos para seus autores e usuários. Por isso, o Intellectual Propriety Rights (IPR) (apud ARELLANO, 2008) orienta que, nesse caso, deve-se levar em consideração não somente o conteúdo como também qualquer ação relacionada ao software (cópias, encapsulamento de conteúdo, emulação de software, migração de conteúdo) que venha infringir as autorizações de uso específico a quem foi acreditado. Em se tratando do prontuário eletrônico do paciente todos os requisitos são relevantes, já que os registros das condições de saúde de um cidadão demandam maior acurácia no trato com essas fontes, tanto do ponto de vista da integridade de seu conteúdo como também dos aspectos de confidencialidade e confiabilidade no seu acesso.

\subsection{Requisitos estratégias e padrões de preservação digital}

A preservação digital requer a observância de alguns requisitos para que os resultados não venham a ser comprometidos. Os requisitos podem ser de natureza funcional ou não funcional. Bullock (1999); Thomaz e Soares (2004), Formenton, Gracioso e Castro (2015),

\begin{tabular}{l} 
(C) RDBCI: Rev. Digit. Bibliotecon. Cienc. Inf. \\
\hline
\end{tabular}


respaldados nos conceitos do modelo OAIS, identificam nove requisitos mínimos para a preservação digital, a saber:

a) Fixar os limites do objeto a ser preservado definindo-se, claramente, que elementos serão efetivamente mantidos.

b) Preservar a presença física consistindo em proteger o(s) arquivo(s) físico(s), quer dizer, a camada primitiva de suporte da informação a ser representada (arquivos de computador, séries de bits).

c) Preservar o conteúdo assegurando a capacidade de acesso em seu nível mais baixo, por exemplo, texto em ASCII, independente de alterações, modificações e demais variações de fontes e características de leiaute.

d) Preservar a apresentação visual por meio de aplicação de fontes de diferentes formatos e tamanhos, presença de espaço em branco, colunas, margens, cabeçalhos, rodapés, paginação e assim por diante.

e) Preservar a funcionalidade do original, por exemplo, textos verbais, gráficos, áudio e vídeo integrados, formato hipertexto.

f) Preservar a autenticidade garantindo que o objeto acessado seja exatamente aquele que se procura, tendo sido preservado na sua forma original.

g) Acompanhar o objeto digital ao longo do tempo, sendo necessário localizá-lo na edição ou versão correta.

h) Preservar a proveniência, identificando a origem do objeto e detalhando seu histórico, a fim de confirmar sua autenticidade e integridade.

i) Preservar o contexto, mantendo a sua dependência de hardware e software, seus modos de distribuição e seus relacionamentos com outros objetos digitais.

Além desses requisitos, é preciso observar os documentos elaborados pela Câmara Técnica de Documentos Eletrônicos (CTDE) do Conselho Nacional de Arquivos (CONARQ) que tratam sobre os requisitos para sistemas informatizados de gestão arquivística de documentos - e-ARQ Brasil; as Diretrizes para Implementação de Repositórios Digitais Confiáveis de Documentos Arquivísticos e a Orientação Técnica no 3 - Cenários de uso de RDC-Arq em conjunto com o SIGAD. Tais documentos indicam parâmetros para repositórios e/ou sistemas arquivísticos digitais confiáveis de modo que a autenticidade, identidade, integridade, confidencialidade, disponibilidade, acesso e a preservação possam estar garantidas, tendo em vista a perspectiva da necessidade de manutenção dos acervos documentais por longos períodos de tempo ou, até mesmo, permanentemente (CONARQ, 2015). Vale salientar que, embora esses documentos normativos mencionem o prontuário de paciente em seu escopo como tipo documental, não contemplam os requisitos de preservação digital para esse tipo de documento de características particulares, regido até mesmo por normatização específica, a exemplo do Conselho Federal de Medicina (CREMEC) e do Conselho Federal de Enfermagem (COFEN).

Em que concerne às estratégias de preservação digital, Bullock (1999) fez uma revisão de literatura e a organizou em dois grupos: as estratégias de preservação, que englobam

\begin{tabular}{|c|c|c|c|c|c|}
\hline (C) RDBCI: Rev. Digit. Bibliotecon. Cienc. Inf. & Campinas, SP & v. 15 & n. 2 & p. $489-507$ & maio/ago. 2017 \\
\hline
\end{tabular}


migração, emulação, impressão e preservação da tecnologia; e aquelas que "assumem o controle da situação", ou seja, exigem a adoção de padrões, o desenvolvimento de guias, a documentação das fontes e o investimento em infraestrutura - hardware, software e pessoal adequada e/ou parcerias. Além dessas estratégias, a preservação e a curadoria digital demandam, necessariamente, a determinação de metadados digitais. Insere-se, portanto, diretamente na área da representação temática ou indexal e descritiva da informação. No entendimento de Bentes Pinto (2001), a representação temática é compreendida como o conjunto de atividades que buscam identificar, nos textos verbais ou não verbais, as pistas que poderão ser consideradas como melhores indicadoras de seu conteúdo visando à recuperação do documento em si ou dos conhecimentos que neles foram registrados.

A respeito dos metadados, o Working Group on Preservation Metadata (WGPM), da Online Computer Library Center (OCLC), os classifica segundo categorias funcionais ou razões para sua adoção em:

a) Descritivos - para facilitar a identificação e descoberta de fontes.

b) Administrativos - para apoiar o gerenciamento de fontes dentro de uma série.

c) Estruturais - para ligar ou reunir os componentes de um objeto informacional complexo (WGPM, 2001, p. 3).

A UNESCO (2003, p. 94) vai além ao definir que os objetivos da adoção de metadados de preservação digital são:

a) Identificar o material pelo qual o programa de preservação tem responsabilidade.

b) Informar o que seja necessário para manter e proteger os dados.

c) Informar ao usuário, quando aplicável, o que seja necessário para reapresentar o objeto pretendido, ou seus elementos essenciais definidos, independentemente de mudanças nas tecnologias de armazenamento e acesso.

d) Registrar o histórico e os efeitos dos fatos relativos ao objeto.

e) Documentar a identidade e a integridade dos objetos para garantir sua autenticidade.

f) Permitir ao usuário e ao programa de preservação entender o contexto do objeto.

Innarelli (2007, p. 71) complementa dizendo que a preservação digital "[...] não se restringe ao estudo de mídias, técnicas de backup, técnicas de migração, técnicas de autenticação etc.". Refere ainda que "Este assunto deve ser estudado de forma interdisciplinar e institucionalmente, cabendo aos profissionais da informação à garantia da preservação e manutenção do documento digital de forma íntegra e autêntica". 
Essas reflexões evidenciam estudos e pesquisas envolvendo a questão da preservação digital voltada a prontuários eletrônicos do paciente, posto se tratar de um documento ímpar para a preservação da memoria da saúde no mundo.

\subsection{Alguns padrões de preservação e curadoria digital}

Em que concerne aos modelos e padrões de preservação digital, encontramos vários, destacando-se entre eles: Open Archival Information System (OAIS), Modelo Trusted Digital Repository (TDR), Preservation Metadata: Implementation Strategies (PREMIS). Neste artigo, iremos nos dedicar apenas ao Modelo OAIS.

O Open Archival Information System (OAIS) é um modelo de referência conceitual, considerado ainda como um sistema aberto para arquivamento da informação que disciplina a preservação e manutenção no acesso às informações em longo prazo. Ele foi encomendado pela International Organization for Standardization (ISO), desenvolvido e coordenado pelo Consultative Committee for Space Data Systems (CCSDS), no ambiente da NASA. Em 2003, tornou-se norma internacional, denominada ISO 14721:2003, com o objetivo de estabelecer um sistema de arquivamento de informações por meio de um diagrama organizacional composto de pessoas que aceitam a responsabilidade de preservar as informações e disponibilizá-las para uma comunidade designada (SOUZA, et al., 2012).

O OAIS é constituído por quatro entidades: Produtores, Consumidores, Administração e o Arquivo propriamente dito. Os produtores fornecem a informação a ser preservada. Os consumidores usam a informação preservada. Uma classe especial de consumidores é a comunidade-alvo (conjunto de consumidores capazes de compreender a informação preservada). A administração é a entidade responsável pelo estabelecimento das políticas mais gerais do arquivo, mas não se envolve com a rotina do arquivo (esta atividade é desempenhada por uma função dentro do próprio arquivo). A Figura 1, a seguir, ilustra esse ambiente.

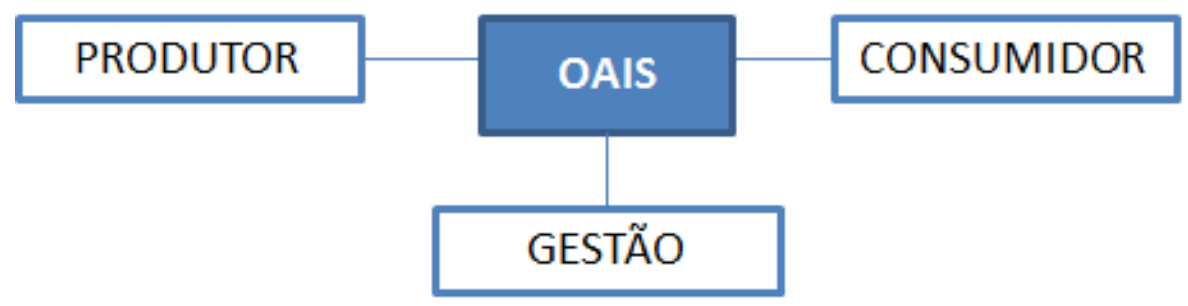

Figura 1 - O contexto de um modelo OAIS

Fonte: NASA/CCSDS, 2012.

O modelo funcional OAIS é mais amplo e composto de seis grandes blocos de processos dentro de um arquivo de preservação digital: ingestão, armazenamento, gestão de dados, administração, planejamento de preservação e acesso (Figura 2). 


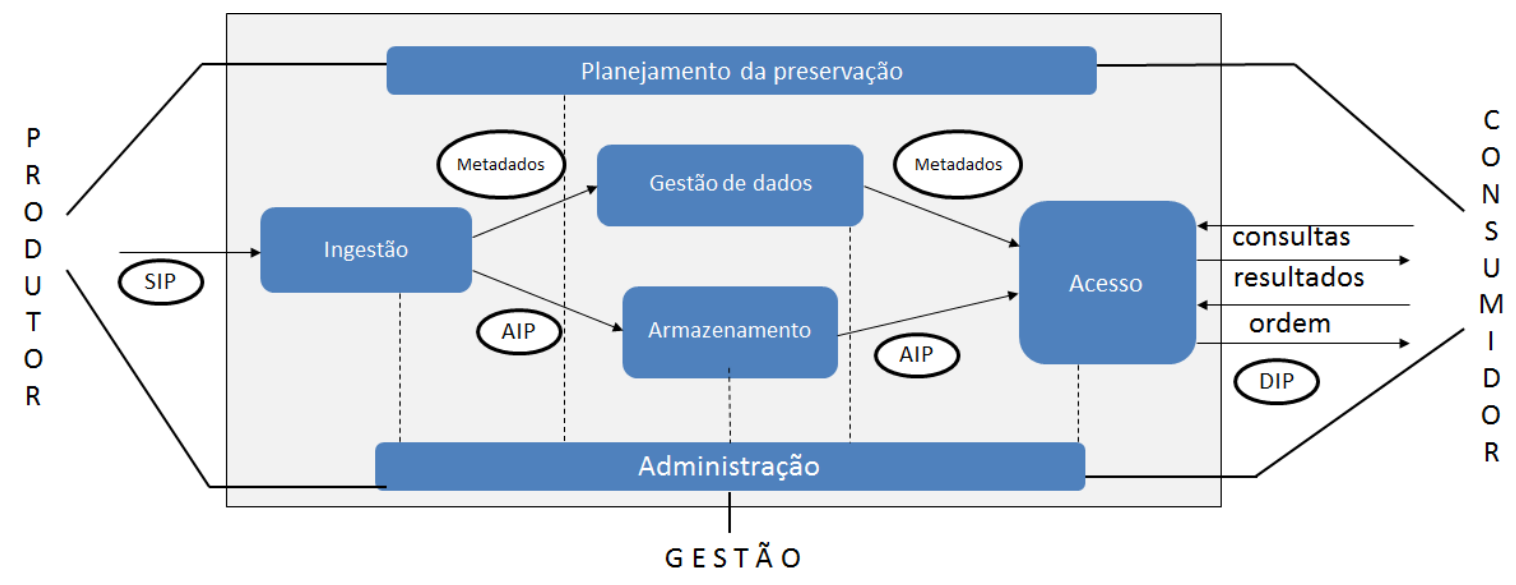

Figura 2 - Esquema funcional do modelo OAIS

Fonte: NASA/CCSDS, 2012.

As entidades funcionais gerenciam o fluxo de informação entre as entidades que formam o ambiente OAIS e identificam os componentes funcionais dos arquivos relacionados com a preservação dos objetos digitais (ARELLANO, 2008, p. 20).

É importante também entender o modelo de informação para inserção dos metadados de preservação de informação digital por longo prazo que o esquema OAIS incluiu. Esse padrão leva em consideração que a criação e o desdobramento de metadados de preservação tendem a ser um componente-chave para a maioria das estratégias de preservação digital.

\section{ESTUDO EMPÍRICO}

Como já mencionamos nesse artigo, as experiências de preservação digital vêm sendo colocadas em prática no contexto da memória cultural, científica e tecnológica. Por isso, julgamos necessária a aplicação dessa tecnologia nas organizações de saúde, particularmente no acervo documental relativo às ações de cuidados de uma pessoa enferma.

O corpus do estudo foi constituído de 01 (um) Prontuário Eletrônico do Paciente (cinco volumes), da especialidade nefrologia, tendo-se como recorte/delimitação do estudo o ano de 1970, para contemplar a legislação brasileira sobre a guarda desses documentos cujo "[...] prazo mínimo [é] de 20 (vinte) anos, a partir do último registro, para a preservação dos prontuários [...]" (BRASIL, 2002, p. 2). Em razão de o prontuário estar registrado em suporte analógico (papel) e organizado em cinco volumes, com cerca de 500 (quinhentas) páginas, solicitamos ao SAME permissão para procedermos a sua digitalização tendo em vista facilitar o manuseio e estudo dessa documentação visando à construção de uma proposta inicial de preservação digital específica para esse tipo de documento. 
O locus do estudo empírico é o Serviço de Arquivo Médico e Estatística (SAME) do Hospital Universitário Walter Cantídio (HUWC) da Universidade Federal do Ceará (UFC), que é financiado pelo Sistema Único de Saúde (SUS) e referência em transplante de rins, razão que motivou a escolha dos prontuários dessa especialidade.

\subsection{Corpus de pesquisa: prontuário eletrônico do paciente}

O prontuário do paciente é um documento redigido pela equipe multiprofissional da saúde em suas ações de cuidados para com a pessoa enferma. Integram essa documentação os registros de dados, informações e conhecimentos clínicos e não clínicos que passam a constituir a chamada Documentação Sanitária. Conforme prescreve a Resolução no 1.638/2002, de 9 de agosto de 2002, do Conselho Federal de Medicina (CFM), é considerado prontuário o

[...] documento único constituído de um conjunto de informações registradas, geradas a partir de fatos, acontecimentos e situações sobre a saúde do paciente e a assistência prestada a ele, de caráter legal, sigiloso e científico, que possibilita a comunicação entre membros da equipe multiprofissional e a continuidade da assistência prestada ao indivíduo.

Embora o prontuário do paciente tenha propriamente a função de documentação clínica, ele também está inserido na gama de documentos para uso das organizações de saúde em sua função assistencial, gerencial, didática, de pesquisa e como um documento financeiro e legal. Conforme o relatório final do Grupo de Expertos en Información y Documentación Clínica da Espanha (GEIDCESP, 2001, online),

La información clínica [que está registrada na documentación clínica] forma parte, también en buena medida, del proceso de participación activa de los pacientes o usuarios en la toma de decisiones clínicas. En este sentido, lo primero que hay que señalar es que la información constituye un proceso de relación y es, por tanto, un proceso dialógico, hablado, en el cual se produce una continua interacción e intercambio de información entre el sanitario y el paciente.

Assim sendo, conforme o Professor Casabona et al. (2006), estão incluídos na documentação clínica, além dos textos verbais, aqueles considerados não verbais, como por exemplo: os exames de imagem, os valores de referência relativos aos exames químicos e laboratoriais. As funções da documentação clínica são, dentre outras, facilitar e melhorar a assistência ao paciente, agilizar e favorecer a comunicação entre a equipe multiprofissional e entre ela e o paciente, além de ser fonte de informação para as pesquisas e estudos clínicos e epidemiológicos que poderão ser utilizados nos processo de educação, gestão e inspeção dos organismos de auditoria sanitária. O prontuário é também uma fonte que expressa os indicadores de saúde.

Em que concerne à documentação não clínica, mesmo que ela seja fundamental no processo assistencial, não está relacionada com dados de saúde. São exemplos desse tipo de documentação aquelas referentes às atividades administrativas, nutricionais, de farmácia, de manutenção, protocolos, dietas etc. No entendimento de Casabona et al. (2006, p. 142), todos os dados, informações e conhecimentos gerados dentro das organizações de saúde são

\begin{tabular}{l|c|c|c|c|c}
\hline (C) RDBCI: Rev. Digit. Bibliotecon. Cienc. Inf. & Campinas, SP & v.15 & n.2 & p. 489-507 & maio/ago. 2017 \\
\hline
\end{tabular}


sanitários, embora nem sempre sejam clínicos. Essa documentação está relacionada com a gestão de serviços e com os pacientes. No primeiro caso, encontramos os pedidos de material, contratos, escalas de plantão, solicitação de férias, protocolos, contratos, vocabulários controlados ou tesauros etc. Já no segundo caso de documentação - relacionada com os pacientes - encontram-se as receitas, pedidos de exames, encaminhamentos para especialistas, relatório de alta, dados relativos aos planos de saúde etc. Corroborando essa ideia, Bentes Pinto (2014, p. 5), entende a documentação sanitária como sendo um

[...] tipo bem particular que foge às características de outro tipo de literatura cinzenta -, a começar pela proteção de acesso assegurada por legislação geral e específica. $\mathrm{O}$ entendimento sobre essa documentação se faz necessário a fim de que ela venha ser representada e organizada de modo a atender as necessidades de quem a busca, respeitando-se o ordenamento jurídico de cada país e também internacional, a exemplo da Constituição, Lei de Acesso a Informação, Declaração Universal do Direito do Homem e da Declaração Universal do Genoma humano.

Por sua vez, os aspectos legais relativos ao prontuário envolvem: autoria, propriedade do prontuário, autorização de acesso, confidencialidade, confiabilidade, segurança e preservação, abaixo descritos:

a) Autoria - podemos considerar que a autoria de elaboração do prontuário é coletiva, posto que a equipe multiprofissional da saúde (médicos, enfermeiros, técnicos de enfermagem, fisioterapeuta, ou, ainda psicólogos e assistentes sociais) escreve nesses documentos. Alguns fazem anotações de dados brutos; outros interpretam as narrativas dos pacientes e acrescentam seus conhecimentos ao decodificarem as mensagens por eles emitidas, ou, ainda, informações oriundas de seus conhecimentos profissionais. Assim, a redação do prontuário é, de certo modo, coletiva.

b) Acesso - embora o prontuário seja do paciente, seu acesso demanda cuidados especiais e é assegurado por legislação referente à deontologia das áreas da saúde, a exemplo do Conselho Federal de Medicina (CFM) e do Conselho Federal de Enfermagem (CFEN). Além desses, no caso brasileiro, o acesso a essa documentação é assegurado pelo inciso $\mathrm{X}$ do artigo 5ํำ da Constituição Federal de 1988 que defende: "são invioláveis a intimidade, a vida privada, a honra e a imagem das pessoas, assegurado o direito a indenização pelo dano material ou moral decorrente de sua violação" (BRASIL...1988, p. 2). Entende-se, portanto, que esse direito é de relevância indubitável. Existem várias outras legislações que preveem a inviolabilidade da intimidade, da privacidade, como o Código Penal, Código Civil, Lei das Contravenções Penais, Códigos de Ética, Declaração Universal dos Direitos Humanos, entre outros.

c) Confidencialidade - pode-se dizer que se refere à distinção entre o público e o privado. É a garantia que o médico e os demais profissionais da equipe devem ao paciente quanto à segurança de que seus dados não serão revelados sem seu consentimento.

d) Confiabilidade - pauta-se na confiança que os pacientes depositam nos registros feitos pelos médicos e outros profissionais da equipe multiprofissional de cuidados do paciente.

\begin{tabular}{c|c|c|c|c|c}
\hline (C) RDBCI: Rev. Digit. Bibliotecon. Cienc. Inf. & Campinas, SP & v.15 & n.2 & p. 489-507 & maio/ago. 2017 \\
\hline
\end{tabular}


e) Segurança - garantia de que os dados registrados nos prontuários ou nos documentos que o compõem estejam protegidos. Uma das opções que já está sendo utilizada para a segurança dos dados gerados nos PEP é a criptografia.

f) Preservação digital - atenta para os cuidados necessários à manutenção da integridade do que foi registrado nos prontuários eletrônicos do paciente e naqueles que estão no suporte analógico.

\section{RESULTADOS PRELIMINARES}

A partir dos estudos da literatura sobre o modelo OAIS, percebemos que, independentemente do tipo de documentação, o planejamento de um projeto de preservação digital é complexo, posto que envolve uma quantidade enorme de variáveis em todo o seu desenvolvimento e acompanhamento a longo prazo.

Concernente à possibilidade de aplicabilidade ao Prontuário Eletrônico do Paciente (PEP), que traz registrada as informações e conhecimentos de todas as ações de cuidados empreendidas em prol da saúde de uma pessoa enferma e que poderá servir de fonte de pesquisa, inclusive para o Big data em saúde, tal preservação se apresenta mais complexa ainda. Nesse sentido, consideramos, entre outras, as seguintes variáveis: multiterminológicas, de metadados de representação temática, descritiva, de acesso e recuperação da informação, jurídicas, financeiras e legais, políticas, estratégicas, educacionais e de pesquisa, de gestão, interoperabilidade, segurança, autenticidade, privacidade, confiabilidade, confidencialidade dos dados do paciente e o sigilo profissional. Por isso, na preservaçao digital do PEP, ademais todas essas variáveis, ainda se faz necessária a observância às características particulares relativas às questões legais de acesso a esses documentos.

Assim, seguindo tal padrão, constatamos que, no caso dos prontuários, a proposta de preservação leva em conta a mesma estrutura, porém, naturalmente, adaptada à realidade desses documentos, conforme a seguir:

a) Produtor - consideramos a equipe multiprofissional da saúde, posto que ela produz e registra dados, informações e conhecimentos no prontuário do paciente.

b) Consumidores - entendemos que são os usuários reais e potenciais: equipe multiprofissional de saúde, Ministério da Saúde, Paciente, Pesquisadores (devidamente autorizados) e estudantes da área de Saúde, de modo geral.

c) Gestão - na proposta desta pesquisa, refere-se ao SAME por ser a Unidade de Documentação Sanitária que gerencia e define as políticas de preservação nas organizações de saúde, obviamente seguindo o ordenamento legal do Conselho Federal de Medicina, da Constituição, do Código Civil, da Declaração Universal dos Direitos Humanos, da Lei de Acesso à Informação e das políticas nacionais de preservação. Para melhor compreensão,

\begin{tabular}{c|c|c|c|c|c}
\hline (C) RDBCI: Rev. Digit. Bibliotecon. Cienc. Inf. & Campinas, SP & v.15 & n.2 & p. 489-507 & maio/ago. 2017 \\
\hline
\end{tabular}


elaboramos o esquema funcional para a preservação digital desses documentos, conforme a Figura 3.

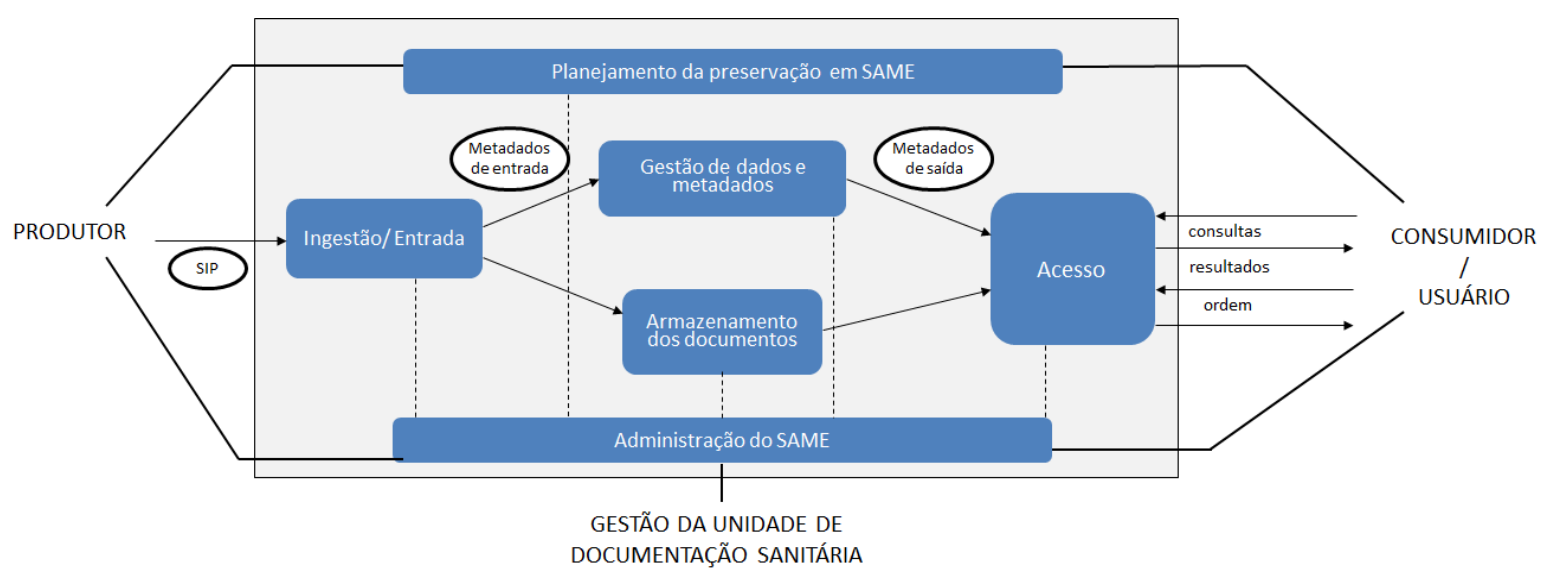

Figura 3 - Aplicabilidade do Modelo OAIS para o SAME

Fonte: Adaptado do Modelo OAIS.

Em que concerne aos componentes internos da aplicabilidade do modelo OAIS, adaptamos os seis blocos de tal modelo em ingestão/entrada, armazenamento dos documentos, gestão de dados e metadados, acesso e planejamento da preservação em SAME, como se segue:

a) Ingestão: é o primeiro módulo do sistema de preservação, considerado nesta pesquisa a entrada dos prontuários. Por se tratar de documentação regida por ordenamento jurídico, essa entrada somente é efetivada após o aval da Comissão de Prontuários de cada instituição de saúde, visando a garantir a procedência e a integridade do documento bem como a revisão e validação da redação dos prontuários. Tal ação vai se configurar no chamado Pacote de Submissão de Informação (SIP). Essa avaliação é necessária, porque, conforme prescreve o Conselho Federal de Medicina em sua Resolução no 1.931/2009, Art. 87, "É vedado ao médico [...] Deixar de elaborar prontuário legível para cada paciente” (BRASIL. CFM, 2009).

Do mesmo modo, a Resolução COFEN nº 311/09, em sua Seção II - Art. 72, alude que os profissionais de enfermagem devem "Registrar as informações inerentes e indispensáveis ao processo de cuidar de forma clara, objetiva e completa" (BRASIL. CFEN, 2007). Outra atenção considerada relaciona-se ao controle de possíveis vírus que poderão danificar as informações registradas. Depois desse controle, é feita a extração de metadados relacionados à identificação do paciente, diagnóstico, evoluções, relatório de alta etc. Nessa etapa, faz-se necessário garantir a autenticidade do documento, adotando-se assinatura digital ou checksum, para assegurar a sua integridade. Somente após essa rigorosa análise, é que o prontuário pode ser enviado para o armazenamento. 
b) Armazenamento dos documentos: Nessa fase, tal qual a anterior, deve-se ter toda a atenção de modo que se garanta autenticidade, segurança, integridade e confidencialidade/privacidade, tendo-se, ainda, o cuidado com a duplicidade das cópias.

c) Gestão de dados e metadados: Nesse bloco é feito o gerenciamento dos metadados descritivos e temáticos definidos na ingestão/entrada, visando garantir, de forma padronizada, todo o conteúdo registrado no documento, a fim de facilitar a preservação e a curadoria dessa documentação no SAME.

d) Acesso: Por se tratar de prontuários cujo acesso é de certa forma restrito, deve-se atentar para a necessidade de interface que indique o acesso por meio de senha que certifique e garanta legalmente a autenticidade, segurança, integridade, confidencialidade/privacidade dos documentos e dos metadados atribuídos.

e) Planejamento da preservação em SAME: É responsável pelo monitoramento das tecnologias (hardware e software) visando à atualização do sistema de preservação dos prontuários. Para tanto, elabora e decide as políticas a serem adotadas na organização de saúde que devem estar em consonância com as políticas de saúde do Estado-Nação.

Todos esses módulos deverão estar em simbiose a fim de que o fluxo de informação e de comunicação do sistema de preservação de prontuários do paciente se efetive com o menor ruído possível e assegure os aspectos legais de autenticidade, segurança, integridade, confidencialidade/privacidade dos documentos e dos metadados atribuídos. Ademais, ratifique a interoperabilidade entre cada um desses módulos.

\section{ALGUMAS CONCLUSÕES}

A preservação e a curadoria digital são temas que, de modo geral, ainda estão em aberto na área de conhecimento da Ciência da Informação. Aplicando-se esse conceito ao campo da Saúde, particularmente, à esfera do Prontuário Eletrônico do Paciente, esse fosso é ainda maior por se tratar de uma documentação muito particular e regida por legislação específica que envolve a equipe multiprofissional da saúde como produtora dos prontuários dos pacientes e responsáveis pelas informações neles registradas; as organizações de saúde como responsáveis pela custódia desses documentos; os pacientes e os consumidores reais e potenciais que poderão acessar tais documentos, desde que sigam a legislação específica.

Conforme os resultados de nosso estudo, verificamos que o modelo de referência OAIS, embora tenha sido proposto para a preservação da memória científica e da cultura, pode ser perfeitamente aplicado ao espaço do SAME, notadamente na documentação sanitária, como é o caso do prontuário do paciente. Contudo, devem ser observados os aspectos relativos à garantia da preservação dos prontuários e levados em consideração seus aspectos legais, além de sua autenticidade, confiabilidade, integridade, confidencialidade/privacidade, auditabilidade, assinatura eletrônica e devida guarda.

Esse trabalho é o 'pontapé inicial' de estudos que contemplam a importância e os meios

\begin{tabular}{l|c|c|c|c|c}
\hline (C) RDBCI: Rev. Digit. Bibliotecon. Cienc. Inf. & Campinas, SP & v.15 & n.2 & p. 489-507 & maio/ago. 2017 \\
\hline
\end{tabular}


a serem utilizados para a preservação digital de Prontuários Eletrônicos de Paciente através do desenvolvimento de um Sistema de Gestão de Prontuários Eletrônicos ou Repositório que estejam em conformidade com o padrão OAIS. Trata-se, portanto, de um estudo ainda incipiente acerca desse tema. Logo, urge que estudos e pesquisas evolvendo esse tema sejam cada vez mais incentivados nos programas de pós-graduação da Ciência da Informação, nos quais seja contemplada a interdisciplinaridade com as Ciências da Saúde, Computação, Direito, Arquivologia, entre outras.

\section{REFERÊNCIAS}

ARELLANO, M. Critérios para a preservação digital da informação científica. Tese (doutorado) - Universidade de Brasília, Departamento de Ciência da Informação, 2008. Disponível em:

<http://bdtd.bce.unb.br/tedesimplificado/tde_busca/arquivo.php?codArquivo=4547>. Acesso em: 20 mar. 2015.

BENTES PINTO, V. A contribuição da terminologia para a gestão da documentação sanitária em organizações de saúde. In: MEDINFOR, 3., 2014, Salvador. Anais... Salvador: UFBA, 2014.

BENTES PINTO, V. Indexação documentária: uma forma de representação do conhecimento registrado. Perspect.Cienc. Inf., Belo Horizonte, v. 6, n. 2, p. 223-234, jul./ dez. 2001.

BRASIL. Constituição da República Federativa do Brasil. Brasília: Câmara dos Deputados, Edições Câmara, 1988. Disponível em: 〈http://www.planalto.gov.br/ccivil_03/Constituicao/Constituicao.htm>. Acesso em: 26 mai. 2015.

BRASIL. CONSELHO FEDERAL DE ENFERMAGEM. Resolução no 311/2009. Aprova a Reformulação do Código de Ética dos Profissionais de Enfermagem. Disponível em: $<$ http://www.portalcofen.gov.br/2007/materias.asp?ArticleID=7323\&sectionID=37>. Acesso em 10 ago. 2016.

BRASIL. CONSELHO FEDERAL DE MEDICINA. Código de Ética Médica, 2009: Resolução CFM no 1.931/2009. Aprova o Código de Ética Médica. Diário Oficial da União. 24 set. 2009. Disponível em:

<http://www.portalmedico.org.br/resolucoes/cfm/2009/1931_2009.htm>. Acesso em: 26 jan. 2015.

BRASIL. CONSELHO FEDERAL DE MEDICINA. Resolução CFM no 1.638/2002. Define prontuário médico e torna obrigatória a criação da Comissão de Revisão de Prontuários nas instituições de saúde. Diário Oficial da União, Brasília, 9 ago. 2002. Disponível em: < http://www.portalmedico.org.br/resolucoes/cfm/2002/1638_2002.htm>. Acesso em: 10 jan. 2015.

BRASIL. CONSELHO NACIONAL DE ARQUIVOS. Câmara Técnica de Documentos

\begin{tabular}{l|c|c|c|c|c}
\hline (C) RDBCI: Rev. Digit. Bibliotecon. Cienc. Inf. & Campinas, SP & v.15 & n.2 & p. 489-507 & maio/ago. 2017 \\
\hline
\end{tabular}


Eletrônicos. Carta para a preservação do patrimônio arquivístico digital: preservar para garantir o acesso. Brasília: CONARQ, 2009. Disponível em:

<http://www.conarq.arquivonacional.gov.br/media/carta.pdf. >. Acesso em: 26 jan. 2015.

BRASIL. CONSELHO NACIONAL DE ARQUIVOS. Câmara Técnica de Documentos Eletrônicos. Diretrizes para a implementação de repositórios arquivísticos digitais Confiáveis. Brasília: CONARQ, 2015. Disponível em: <

http://conarq.gov.br/images/publicacoes_textos/diretrizes_rdc_arq.pdf.>. Acesso em: 16 mar. 2017.

BULLOCK, A. Preservation of digital information: issues and current status. Ottawa: National Library of Canada, april 22, 1999. Last updated on feb. 27, 2001. Disponível em: <http://www.collectionscanada.gc.ca/9/1/p1-259-e.html >. Acesso em: 20 dez. 2014.

CASABONA, C. M. R. et al. Aspectos jurídicos de los datos de salud y de los datos genéticos. In: La ética y el derecho ante la biomedicina del futuro. Bilbao: Universidad de Duesto, 2006.

DERRIDA, J. Mal d'Archive: une impression freudienne. Paris: Galilée, 1995.

FLORES, D.; HEDLUND, D. A Preservação do patrimônio documental através da produção de instrumentos de pesquisa arquivísticos e da implementação de repositórios arquivísticos digitais. Série Patrimônio Cultural e Extensão Universitária, IPAHN, p. 33. 2014.

FORMENTON, D.; GRACIOSO, L. S.; CASTRO, F. F. Revisitando a preservação na perspectiva da ciência da informação: aproximações conceituais. Rev. Digit. Bibliotecon. Cienc. Inf., Campinas, SP, v.13, n.1, p.170-191, jan/abr. 2015. Disponível em: <http://www.sbu.unicamp.br/seer/ojs/index.php/rbci>. Acesso em: 01 nov. 2016.

GEIDCESP. Documento final del Grupo de Expertos en Información y Documentación Clínica, actualizado en 23/01/2001. Disponível em: <http://www.medynet.com/usuarios/jraguilar/documentacionclinica.htm>. Acesso em: 12 de fev. 2015.

HEDSTROM, M. Preservação digital. Argumentos e requerimentos em RGL de Instituições Membros. 1996. Disponível em: <http://www.oclc.org/home.en.html.>. Acesso em: 10 jan. 2015

INNARELLI, H. C. Os dez mandamentos da preservação digital. In: SANTOS, V. B.; INNARELLI, H. C.; SOUSA, T. R. B. Arquivística: temas contemporâneos. Brasília: SENAC, 2007.

KRUPPA, S.M.P. Sociologia da educação. São Paulo: Cortez, 1994

NASA/CCSDS. Reference model for an open archival information system (OAIS). Washington: Magenta books, 2012. Disponível em: <http://public.ccsds.org/publications/archive/650x0m2.pdf >. Acesso em: 14 jul. 2015.

\begin{tabular}{l|l|l|l|l|l} 
(C) RDBCI: Rev. Digit. Bibliotecon. Cienc. Inf. & Campinas, SP & v.15 & n.2 & p. 489-507 & maio/ago. 2017 \\
\hline
\end{tabular}


SILVA, S. C. A. Algumas reflexões sobre preservação de acervos em arquivos e bibliotecas. Rio de Janeiro: Centro de Memória da Academia Brasileira de Letras, 1998. Disponível em: 〈http://www.arqsp.org.br/cpba/cadtec/comtec_sas1.htm>. Acesso em: 21 jul. 2015.

SOUZA, A. H. L. R et. al. O modelo de referência OAIS e a preservação digital distribuída. Ci. Inf., Brasília, DF, v. 41 n. 1, p.65-73, jan./abr., 2012.

TAVARES, M. F. D. Preservação digital: entre a memória e a história. Ci. Inf., Brasília, DF, v. 41 n. 1, p.9-21, jan./abr., 2012.

TÉRMENS, M. Preservación digital. Barcelona: Editorial UOC, 2013.

THOMAZ, K. P.; SOARES, A. J. A preservação digital e o modelo de referência Open Archival Information System (OAIS). DataGramaZero, Rio de Janeiro, n. 1, v. 5, fev. 2004. Disponível em: <http://www.dgz.org.br/fev04/F_I_art.htm>. Acesso em: 01 nov. 2016.

UNESCO. Guidelines for the preservation of digital heritage. 2003 Disponível em: <http://unesdoc.unesco.org/images/0013/001300/130071e.pdf > . Acesso em: 14 jan. 2015.

UNESCO. Some aspects of UNESCO 's role with respect to bibliographic control 1945-1965. Paris: UNESCO, 1967

WATERS, D.; GARRETT, J. Preserving digital information: Report of the Task Force on Archiving of Digital Information commissioned by the Commission on Preservation and Access and the Research Libraries Group. Washington, DC: Commission on Preservation and Access. 1996.

WORKING GROUP ON PRESERVATION METADATA - PMWG. Preservation metadata for digital objects: a review of the state of the art. [S.1.]: Online Computer Library Center - OCLC, jan. 31, 2001. Disponível em:

<http://www.oclc.org/content/dam/research/activities/pmwg/presmeta_wp.pdf $>$. Acesso em: 6 dez. 2014.

\section{AGRADECIMENTOS}

Agradecemos ao CNPQ pelo apoio de bolsa. 


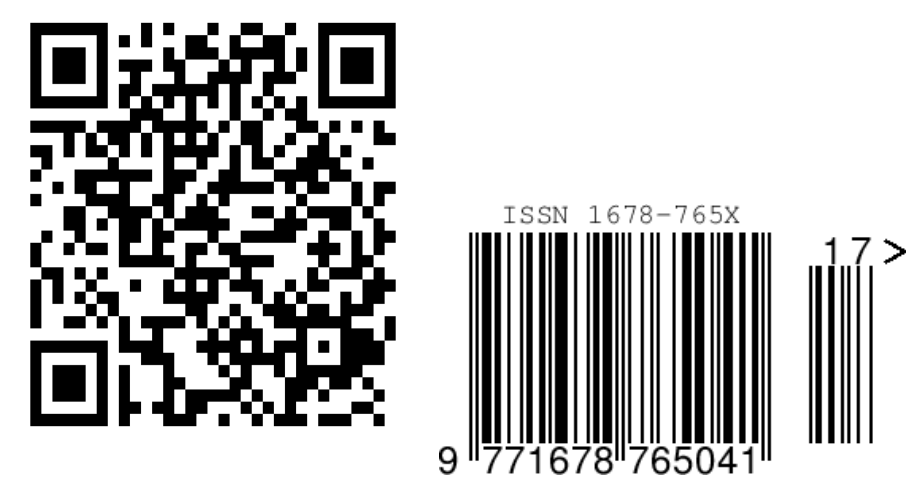

